\title{
CANDIDATE REGISTRATION SYSTEM AND RESULTS TRANSMISSION SYSTEM ON CREDIBILITY OF THE ELECTORAL SYSTEM IN KENYA; A CASE STUDY OF NAIROBI COUNTY
}

\author{
Owino Patience Marjorie ${ }^{\mathrm{a}}$, Dr. James Mwikya Reuben ${ }^{\mathrm{b}}$, \\ ${ }^{a}$ Department of Business Administration, Management University of Africa, \\ P.O Box 29677-00100, Nairobi Kenya \\ ${ }^{\mathrm{b}}$ Department of Computing and Information Technology, Kirinyaga University, \\ P.O.Box: 143-10300, Kerugoya Kenya \\ ${ }^{\mathrm{a}}$ marjorie.owino@gmail.com \\ b jamesrbn2@gmail.com
}

\begin{abstract}
In a multi-party democracy, it is expected from both the elected and appointed government officials at all levels of the political system to render periodic accounts of their stewardship to the population. There has been recurring post-election violence in Kenya due to disputed elections. The announcement of the disputed 2007 presidential election results in Kenya on December 27th, 2007 led to what could be described as the worst political crisis in Kenyan postcolonial history. This study was guided by the following specific objectives; to assess the effect of Candidate Registration System (CRS) on the credibility of the Electoral System in Nairobi County and to evaluate the effect of Results Transmission System (RTS) on the credibility of the Electoral System in Nairobi County. The study was anchored on Technology Acceptance Theory and employed a descriptive research design. The target population was 2,251,929 registered voters in Nairobi County and 40 Independent Electoral and Boundaries Commission, technical officials. A sample size of 351 respondents was used determined using Fisher's (2007) formula. Primary data for this study was collected using structured questionnaires. The analysis involved both descriptive statistics and inferential statistics. The inferential results showed a positive correlation of $(r=0.554, p=0.000)$ between Candidate Registration System $(C R S)$ and credibility of electoral systems. Findings on Results Transmission System (RTS) and credibility of electoral systems showed a positive correlation of $(r=0.648, p=0.000)$. Furthermore there was a significant effect between Candidate Registration System (CRS) and credibility of electoral systems $(\beta=.152, p=0.000)$, and on Results Transmission System (RTS) and credibility of electoral systems $(\beta=.155, p=0.000)$. The study concluded that Candidate Registration System $(C R S)$ and Results Transmission System (RTS) are critical in producing high-quality, tamperresistant voter ID cards and electoral results. The study recommends that there should be adequate policy and strict protocols for supervision, management, transmission and storage of electoral data.
\end{abstract}

Keywords: Candidate Registration System (CRS), Results Transmission System (RTS), credibility of the Electoral System 


\section{Introduction}

Statistics Canada, opines that technology is a field of work and study that includes technologies such as the desktop and laptop computers, software peripherals, and connections to the internet primarily for information processing and communications functions (Alhassan, 2018). This conceptualization points to the fact that technology involves the use of computer software and hardware to process information for both private and public use (Lindner, 2018). Studies reveal that the usage of technology in elections has eliminated the incidents of multiple registrations which had been one of the main political tools for rigging elections by unscrupulous and savage elements (Okokpujie, John, Noma-Osaghae, Ndujiuba \& Okokpujie, 2019). According to Van Holsteyn (2018), the goal of elections is not simple to determine the winners and losers, but also to give legitimacy to the winners, even for those voters who did not vote for them. Part of that is that elections are governed by impartial and independent, transparent and accountable electoral management bodies. The introduction of information and communications technologies (ICTs) into the electoral process is generating both interest and concern among voters and practitioners across the globe. Technology has undoubtedly helped electoral management bodies to make their processes more efficient. As indicated by Jacobsen (2019), increased Internet penetration, even in developing countries with poor communications infrastructure is enabling Electoral Management Bodies (EMBs) to be more effective at communicating internally and with all the stakeholders involved in the process. Technology is also playing an increased role in enhancing the integrity and credibility of electoral processes and strengthening trust between stakeholders (Iwuoha, 2018).

According to Ashwini, Ashwini, Belavatagi, Kumuda, and Bhaskar, 2017), modernization and automation are triggered by a sense of urgency to overcome a certain short-term problem; election administrators have adopted technology over the past years in various countries around the world. Gates (2018) postulates two rules regarding technology, and the first one focuses on the efficiency of a business operation. Automation, which is applied to an efficient business operation, will amplify that efficiency, whereas the second rule focusses on automation of an inefficient business operation which will magnify the inefficiency of that operation. It is, therefore, vital to ensure that an electoral process is efficient before the introduction of any technology to make maximum benefits from it (Rothenberg, 2018). The cost implication of introducing a system into the process should be considered as it does not end at purchasing but requires being set up, maintained and constant consultation with experts (Kanyinga \& Odote, 2019). Infrastructure like electricity, security should also be considered before new technologies are introduced. The EMBs need to involve all the stakeholders in the electoral process, for instance, political parties, media, the general public, parliament as the drafters of laws, etc. According to Achieng and Ruhode (2013), with all the advantages of technology, the EMBs should take cognizant of risks that technology might cause, so that they may mitigate the issues. Alhassan (2018) highlights the conditions to be adhered to in adopting new technologies in elections as; systems authentication, testing, and preservation process avoid illegal access, executing data-gathering processes and methodologies to ensure composed data and verified consistently, proper electoral staff training, imposing privacy policies, stakeholder involvement in building trust on technology. Elections are very intricate as materials have to be procured, for instance, ballot boxes and papers; human resources need to be employed, trained, deployed, and salaried (Dorpenyo, 2019). According to Kerr (2018), the EMBs need to regularly brief the 
media, public and political parties at all times; with these features in an election, ICT can be used to assist in fast-tracking the process to ensure efficiency and effectiveness.

Important aspect of technology in an election is the use of Candidates Registration System (CRS). The CRS ensures that primary data on candidates nominated by political parties are entered in a format that makes it easy for IEBC to verify the accuracy of the candidate details, compliance and generate ballot paper proofs (LWV, Porte \& MAL, 2019). This is achieved by cross-matching the voters' register and political party register. Inconsistencies in the data submitted by political parties have posed a challenge on the processing of ballot proofs such as, Mix up of photos. There have also been inaccuracies in the data submitted by Political Parties such as Use of Nicknames). Overall, CRS strives to: Improve data exchange from Political Parties and Independent candidates to IEBC returning officers Enhance the efficiency of the Nomination process through accurate data capture and processing of records by the Returning officers Improve accuracy of processing of the Ballot papers how CRS works. RTS is a system for transmitting provisional results electronically to an observation centre. At the end of voting and when votes have been counted and tallied, the Presiding Officers (Pos) enter the data on the signed results sheet (Form 35) into a specially configured mobile phones and transmits the results simultaneous to the election results centres at the constituency, county, and national level. RTS is used to: Enhance transparency through electronic transmission of provisional results from the polling stations, display and visualize provisional results at the tally centers and Provide access to provisional elections data to media and other stakeholders in real-time interactive visualization of results.

According to Norris, Cameron, and Wynter (2018), Credible elections are integral to democracy; as preeminent political scientist Charles E. Lindblom once noted, a critical difference between democracy and authoritarianism is that in democratic regimes citizens choose their top policymakers in genuine elections (Birch \& Muchlinski, 2018). A credible poll reflects the will of the people, who accept the election as a vehicle to include their voices in the political process. How do we then measure electoral credibility? Researchers study many aspects of the electoral process to determine the integrity or credibility of the outcome. For example, the Electoral Integrity Project looks at 49 variables, and among these are voter turnout and political finance (von Borzyskowski, 2019). A high level of voter turnout has traditionally been viewed as a reliable indicator of electoral credibility, yet this ignores other critical factors. Examining political finance offers a more detailed picture, but is still highly variable and subject to other intervening variables. Indeed, measuring electoral credibility is a nuanced and complex challenge (Borner, Brunetti \& Weder, 2016). The credibility of elections can be ensured if the state resources the EMB to acquire adequate materials for conducting periodic voter education, purchase appropriate voter materials and equipment (Pressgrove \& Kim, 2018). All these things must be done in consultation and coordination with the important stakeholders in the electoral process. Stringent measures must be put in place such as proof of birth certification during the registration of voters to check the abuse of the process by foreigners. Ineffective voter education can also mar the quality of elections in the country (Morse, 2018). During elections, supreme power lies in the voters who elect their preferred political leaders. In Africa, and one deficiency that the society grapples with is the high illiteracy rate. 
The Independent Electoral and Boundaries Commission (IEBC) is an independent regulatory agency that was founded in 2011 by the Constitution of Kenya. Article 88 of the Constitution of Kenya establishes the Independent Electoral and Boundaries Commission (IEBC) as the body mandated to conduct and supervise elections and referenda in Kenya (Cheeseman et al., 2019). The Commission is responsible for holding and managing referendums and elections to any elective body or office established by the Constitution, and any other elections as prescribed by an Act of Parliament. It was created in a provision of the 2010 constitution and the Independent Electoral and Boundaries Commission Act. The mandates of IEBC includes; the continuous registration of voters and revision of the voteres roll, the delimitation of constituencies and wards, the regulation of political parties process, the settlement of electoral disputes, the registration of candidates for elections, voter education, the facilitation of the observation, monitoring and evaluation of elections, the regulation of money spent by a candidate or party in respect of any poll, the development of a code of conduct for candidates and parties, the monitoring of compliance with legislation on nomination of candidates by parties (Nespeca, Meesters, Comes, Boersma \& Tomaszewski, 2018). The utilization of technology in the 2017 Kenya electoral processes was guided by Section 44 of the Elections Act of 2011. Under Section 44 (1) of the act, the Independent Electoral and Boundaries Commission (IEBC) acquired "an integrated electronic electoral system," referred to as the Kenya Integrated Elections Management System (KIEMS). KIEMS was designed to integrate the existing biometric voter registration (BVR), the biometric voter identification (EVI), the electronic results transmission (RTS), and the candidate registration systems (CRMS). Three sub-systems (CRMS, EVI, and RTS) were part of the 2017 procurement, while the BVR system is what the IEBC used during the 2013 electoral process. The bio-data information of all the registered voters was loaded onto the integrated system, with biometric details of specific voters restricted to polling stations in which they are registered.

\subsection{Statement of the Problem}

There has been recurring post-election violence in Kenya due to disputed elections (Pfeiffer, 2018). The announcement of the disputed 2007 presidential election results in Kenya on December 27th, 2007, led to what could be described as the worst political crisis in Kenyan postcolonial history (Kenny, 2019). This massacre claimed over 1000 lives of children, men, and women, and left about 600,000 Kenyans internally displaced. Different experts have analyzed the immediate and remote causes of the crisis. They established that recurring electoral violence in Kenya since 1992 demonstrated the fluidity of grievance and other factors, which shredded cohesion, exposed the depth of historical injustices, and further polarized the country along ethnic-regional lines. In particular, Laakso (2019) believes that at the core of these grievances is the belief that the electoral body doesn ${ }^{\text {ee }}$ deliver free fair and credible election and that political power provides the ethnic group of the president with exclusive advantages. Historically, the political leaders who direct political powers in Kenya also control the direction and magnitude of the economic and political resources of the state. In the 2017 presidential elections in Kenya, one of the presidential candidates called for a press conference alleging that the IEBC servers had been hacked and algorithm set to ensure an $11 \%$ difference favor of the then incumbent president Uhuru Kenyatta at all levels of results transmission. The centre for intellectual property and information technology (CIPIT) team investigated these allegations but was not able to establish claims based on the evidence presented and recommended a comprehensive audit of the system. The introduction of biometrics technology was meant to ensure the credibility and trust in the 
electoral system. A hacking claim is, therefore, incredibly severe and could damage such credibility irreparably. The reason this accusation gained traction, without evidence, is in part due to the little knowledge available on how the system worked.

Several studies have been conducted on the use of technology in election for example; Cheeseman, Lynch, and Willis (2018) conducted a study which examined the unintended consequences of election technology in Kenya, Uganda, and Ghana and found that growing use of these technologies has been driven by the fetishization of technology rather than by rigorous assessment of their effectiveness; that they may create significant opportunities for corruption that (among other things) vitiate their potential impact; and that they carry significant opportunity costs. The study presented contextual and conceptual gaps. Agbu (2016) conducted a study on Election rigging and the use of technology in Nigeria and found that technological input in Nigerian electoral space made it extremely difficult for results to be manipulated, either by anonymous individuals or through arbitrarily and fraudulently manipulating figures. The study presented conceptual, contextual, and methodological gaps. The current study sought to address these gaps presented by establishing the candidate registration system and results transmission system on credibility of the electoral system in Kenya; A case study of Nairobi County.

\subsection{Specific Objectives of the study}

The following specific objectives guided this study;

i. To assess the importance of Candidates Registration System (CRS) on the credibility of the Electoral System in Kenya.

ii. To evaluate the consequence of Results Transmission System (RTS) on the credibility of the Electoral System in Kenya.

\subsection{Conceptual Framework}

Independent Variables

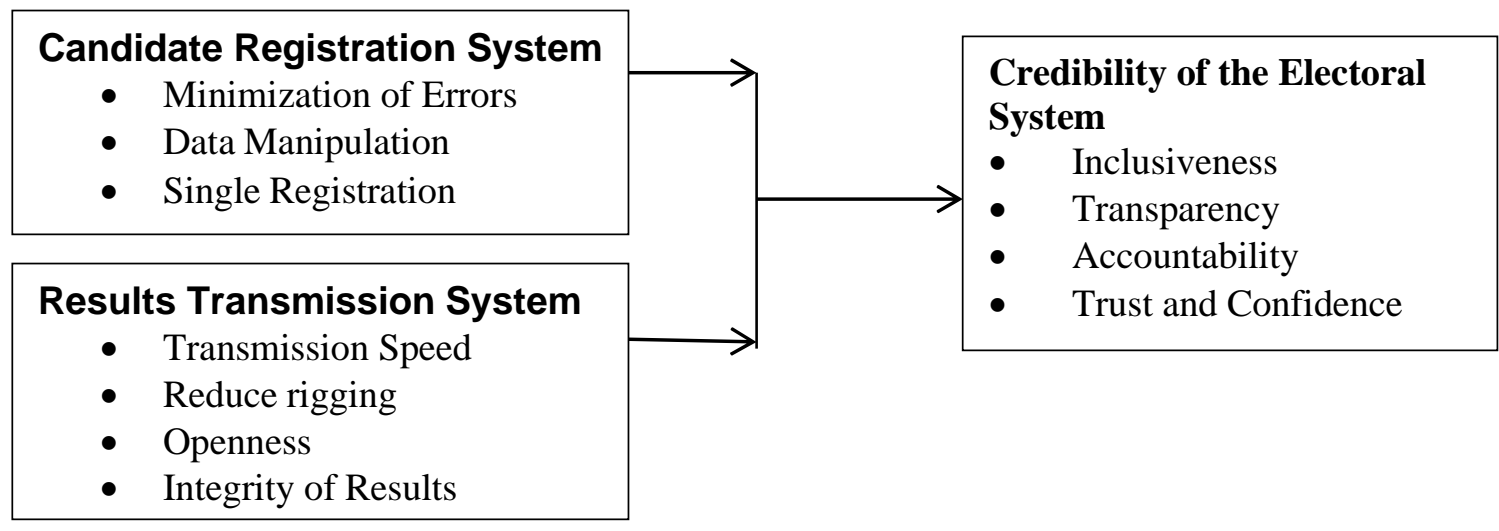

Figure 1.1: Conceptual Framework 


\section{LITERATURE REVIEW}

\subsection{Theoretical Framework}

\subsubsection{Technology Acceptance Theory}

This is the main theory on which this study was underpinned. Technology Acceptance theory was developed by Davis (1989). The theory suggests that when users are presented with a new technology, several factors influence their decision about how and when they will use it (preparedness), notably: Perceived usefulness (PU) defined by Fred Davis (1989) as the degree to which a person believes that using a particular system would enhance his or her job performance. Perceived ease of use was defined by Davis (1989) as the degree to which a person believes that using a particular system would be free from effort. This is an information systems theory that models how users come to accept and use technology. Davis and Venkatesh (1996) add that the Technology Acceptance Theory is influential in predicting user acceptance and users' intentions, as well as the efficient usage of tools in the field of technology. In 1996, Davis and Venketesh made another adjustment to the Technology Acceptance Theory. Bagozzi (2007) found that perceived ease of use and perceived usefulness had a direct effect on behavioral intention and they concluded that users might perhaps use technology even if they do not have favourable attitudes, and they stated that attitude did not entirely mediate the influence of perceived usefulness on the behaviour intention. Thus, Davis and Venketesh (1996) excluded perspectives from the Technology Acceptance theory and postulated that attitudes do not play a significant role in users' behavioural intention to use since they are confined by performance and effort expectancies (Venkatesh, 2003).

According to Momani and Jamous (2017), the Technology Acceptance theory is also an extension of the Theory of Reasoned Action (TRA) done by Davis. It replaced TRA ${ }^{\text {ee }}$ s attitude toward behavior with two technology acceptance measures which are: perceived usefulness and perceived ease of use. Technology Acceptance Theory did not include the TRA ${ }^{\text {ces }}$ subjective norms in its structure. It was developed after the introduction of information systems into organizations. It is formed in the information technology field, while Theory of Reasoned Action (TRA) and Theory of Planned Behavior (TPB) developed in the psychology field so that it is less general than TRA and TPB. The development of technology acceptance theory came through three phases: adoption, validation, and extension. In the adoption phase, it was tested and adopted through a vast number of information system applications. In the context of software use, this provided a mechanism for discussing the current mix of Usefulness and Ease of Use for particular software packages, and for plotting a different course if a different combination is desired, such as the introduction of even more robust software. The Technology Acceptance Theory has been used in most technological and geographic contexts. Some of these contexts are in health care, commerce, and education. This theory was considered relevant to the study in that it helped the researcher understand how the adoption of new technologies by IEBC can improve on their performance and improve on the credibility of the election in Kenya.

\subsection{Empirical Literature Review}

This section presents a review of the various studies that have been conducted previously by other authors and related to the topic of the current study.

\subsubsection{Candidates Registration System (CRS) and Credibility of Electoral System}

Micheni and Murumba (2018) conducted a study to examine the role of ICT in Electoral Processes: Case of Kenya. The main objective of the study was to highlight the types of 
technologies used in electoral systems and results transmission, to investigate the challenges faced in using these technologies in registering candidates, and to establish benefits of technology use in electoral processes. The study was conducted through a desk search on elections materials, elections observer reports, international and Kenyan laws on elections and reports by Kenya's EMB, IEBC. The findings of the study indicated that ICT is a tool which when used appropriately, can help citizens participate in the political affairs of their countries. Through the use of information technologies such as database management systems, biometrics voter registration, and identification, registration of candidates electronically, optical scanning, blockchains, and digital networks, secure and robust systems for digital voting can be devised. The study concluded that legislative and regulatory items that govern elections in African countries need to be reviewed to cope with new and emerging technologies. When considering technological solutions for electoral processes, Election Management Bodies must conduct adequate feasibility studies and proper strategic planning to ensure that they have sufficient plans and time for the introduction of new technologies.

Jones, McAllister, and Gow (2018) in a study revealed that the registration of candidates for election (registration to gain ballot access) confirms a candidate ${ }^{\text {ee }}$ intention to contest a specific election and is often linked to the process of nominating candidates. It is good practice to ensure that the legal framework specifies when, how and where registration procedures must be undertaken, what the requirements for registration are and how the verification of registration will take place. To ensure fairness, the grounds for rejection of a registration application have to be based on objective criteria and have to be clearly stated in the legal framework for elections, along with avenues of appeal against such rejection. Correctly applied, this would protect candidates against arbitrary discrimination. To make sure that the registration procedure, including possible appeals, is finalized well in time for the EMB to print and distribute ballot papers, it is advisable to have a clear and transparent schedule with deadlines by which appeals have to be submitted, etc. in so doing, the credibility of the election will not be questioned by any candidate.

Abodunrin, Oloye, and Alaba (2018) conducted a study dubbed „Technology-Based Device and

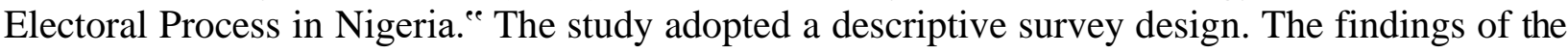
study revealed that electronic registration of candidates ensured reduced cases of electoral malpractices in the electoral system of Nigeria. The study indicated that transparency in the election means openness and accountability, and it is a key feature for the credibility of democratic elections. It was affirmed that an indicator of transparency can be the access by electoral observers, both domestic and international, to all procedures at every stage of the electoral process. With manual processes, transparency is relatively straightforward, as the processes are usually visible, and it is not difficult to provide meaningful access to observers. By contrast, with the use of some technologies, it may be more difficult or even impossible for observers to testify that the outcome is correct. Electronic voting systems are one example where in some cases, it is almost impossible to ensure that the vote that is registered is indeed the vote cast by the voter and, therefore, that the resulting vote-counting is accurate. On the other hand, the use of technology may enhance transparency once the data entry into the respective system is proved to be accurate, and large quantities of data can produce meaningful reports with very few errors. With the use of technologies, transparency may have to be provided in completely different ways depending on the technology. 


\subsubsection{Results Transmission and Presentation and Credibility of Electoral System}

According to a report by IEBC (2019), election results transmission and presentation (RTS) has been a great success. The public has been able to watch live streams of results at the big screens set up by IEBC at observation centres or on national television. It has been used successfully in all by-elections since 2009, the 2010 Referendum, and the last general election. Although the electronic results are "provisional" because they lack legal recognition, the outcomes reflect the final hard copy results. There have been cases of candidates conceding defeat based on the electronic results, although IEBC only declares winners on the hard copy tally. RTS gives quick trends on how the voting went. The report indicated that it is the results from the polling stations with fewer voters that are the first to come in. Where the telecoms service provider signal is weak or absent, the IEBC polling officials use satellite phones or travel to where there is adequate signal presence. The points of transmission are often identified in advance. In some cases, IEBC works with mobile phone service providers to enhance the signals at the polling centres. In addition, the report revealed that during the 2013 March 4th polls in Kenya, only 17,000 of the 33,000 polling stations managed to transmit results before it was overwhelmed by some technical hitches. This alternative way of getting results had to be discontinued when it became too slow, and although the problem was identified and fixed, a number of officials had abandoned the transmission as they took hard copies of the same to tallying centres. The Commission is working towards strengthening the RTS system by setting up faster connectivity and better servers.

A study conducted by Thakur (2015) indicated that technology enhances faster vote counting. In India, counting the results from voting machines takes between two and three hours per constituency, including the time needed for checks, which previously took days for paper votes. It also reduces the scope for human error and saves money through recruiting fewer poll workers. According to Thakur (2015) asserted that results transmission and tabulation are the processes of sending the results of the vote count from polling stations to a central polling office and aggregating them to give total results (at constituency or national level). With paper-based processes, collecting and calculating results from thousands of polling stations country-wide is often the slowest part of the process; with digital technology, results can be transmitted electronically (for example, over the internet or by mobile phone) and aggregated by computer, allowing at least preliminary results to be announced quickly (most countries also carry out paper checks before the outcome is confirmed).

Loeber (2017) examined the use of technology in the election process. The study adopted the use of a survey research design where surveys were sent to electoral management bodies. The survey collected institutional-level data, such as how members of the EMB are appointed. The target population of the study was 1120 electoral officials drawn from over 50 countries. The findings revealed that the use of different forms of technology in the election process has been on the rise. More and more countries use information and communication technology (ICT) to try to improve their election process. The researcher indicated that often when thinking about eenabled elections, there is a tendency to think about e-voting and I-voting only. However, there are many phases during the electoral cycle where some form of ICT can be used. An example that became very clear during the 2008 US presidential elections was the use of electoral campaigning through social media. Many countries in the world, including some of the newer democracies, use forms of electronic voter registration and identification, for example, through 
the use of biometrics. Tabulation and publishing of results can also be done with the use of ICT, as well as (re)districting. When talking about these new technologies, one should be aware that most of the applications that are used are not seen by the voters; since they are only used by the election administrators. Loeber (2017) asserted that the applications used for ensuring the security of data include electoral registers, software for registration of parties and candidates and software for tallying, direct data capture machines and calculating results. However, nowadays, voters are also confronted with ICT solutions in voting in some countries where forms of evoting are introduced. This can range from fairly simple forms such as a scanner that counts the ballot as the voter puts it in the ballot box, to the use of voting computers in the polling station, but also remote voting through the internet. The use of these new technologies raises new challenges for election management bodies (EMBs).

\section{RESEARCH METHODOLOGY}

\subsection{Research Design}

A research design is an approach for a study and the plan by which the strategy is to be carried out (Cooper \& Schindler, 2001). This study adopted a descriptive research design. Cooper and Schindler (2008) demonstrate that the essential features of descriptive that lie in the objectives. If the research is concerned with finding out who, what, where, when, or how much, then the study is descriptive. Descriptive studies are those to describe phenomena associated with a subject population or to estimate proportions of the people that have specific characteristics.

\subsection{Target Population and Sample Frame}

The target population, as defined by Frederic (2010), is a universal representative set of the larger population of all members; the real or hypothetical set of people, events, or objects to which a researcher wishes to generalize the findings. The accessible population, on the other hand, refers to the population in research on which the researchers can apply their findings (Saunders, Lewis, \& Thornhill, 2012). The target population for this study comprised of 2,251,929 registered voters in Nairobi County as per the IEBC voterse ${ }^{\text {ee }}$ register of 2017 and 40 IEBC technical staffs. Table 3.1 shows the target population

Table 3.1: Target Population

\begin{tabular}{ll}
\hline Category & Target Population \\
\hline Registered Voters & $2,251,929$ \\
IEBC Technical Staff & 40 \\
\hline Total & $\mathbf{2 , 2 5 1 9 6 9}$ \\
\hline
\end{tabular}

\subsection{Sample and Sampling Technique}

Orodho and Kombo (2002) observe samples as a limited and set number of people in a population to be observed. Stratified random sampling technique was utilized to sample voters from the constituencies in Nairobi County, while Census approach was used to collect data from the technical staffs since their number was manageable; however, since the population of registered voters in Nairobi County was considered too large, the sample size for the voters was determined using the Fishere's et al. (2007) formula; $\mathrm{n}=\mathrm{Z}^{2} \mathrm{pq} / \mathrm{d}^{2}$

Where $n=$ the desired sample size 
$\mathrm{Z}=$ standard normal deviation at the required confidence level $95 \%$ or 1.96

$\mathrm{P}=$ Business owners and managers, 0.7238 of the entire population of SMEs.

Calculation

$\mathrm{q}=1-\mathrm{p}$ (the proportion without characteristics)

$\mathrm{d}=$ level of statistical significance (degree of freedom $=0.05$ )

$\mathrm{n}=1.96^{2}(0.7238)(0.2762) /(0.05)^{2}$

$\mathbf{n}=307$ Voters

The sample size for this study was 347 respondents.

Table 3.2: Sample Size

\begin{tabular}{lll}
\hline Category & Technique & Sample Size \\
\hline Registered Voters & Stratified Sampling & 307 \\
IEBC Technical Staff & Census & 40 \\
\hline Total & & $\mathbf{3 4 7}$ \\
\hline
\end{tabular}

\subsection{Pilot Testing}

A pilot test is conducted to detect weaknesses in design and instrumentation and to provide proxy data for the selection of a probability sample (Cooper \& Schindler, 2011). The study adopted $10 \%$ of respondents for pilot testing representing 34 respondents. A pilot test is conducted to test for the reliability and validity of the data collection instruments.

\subsubsection{Validity of the Research Instrument}

Validity refers to whether a questionnaire is measuring what it purports to measure (Heale \& Twycross, 2015). To ensure content validity, the questionnaire was subjected to a thorough examination by supervisors in charge of the proposal development. They were asked to evaluate the statements in the questionnaire for relevance. Based on the evaluation, the instrument was adjusted appropriately before subjecting it to the final data collection exercise. Their review comments were used to ensure that content validity is enhanced.

\subsubsection{Reliability of the Instrument}

Heale and Twycross (2015) define reliability as the extent to which results are consistent over time and an accurate representation of the total population under study is referred to as reliability and if the results of a study can be reproduced under a similar methodology, then the research instrument is considered to be reliable. The study adopted Cronbach alpha value of 0.70 to test for the reliability of data. Reliability is the consistency of measurement or the degree to which an instrument measures the same way each time it is used under the same condition with the same subjects. The reliability test results are presented in Table 3.3.

Table 3.3: Reliability Test Results

\begin{tabular}{llll}
\hline Variable & Cronbach Alpha & Items & Comments \\
\hline Candidate Registration System & 0.803 & 6 & Acceptable \\
Result Transmission Systems & 0.763 & 6 & Acceptable \\
Credibility of Electoral Systems & 0.833 & 6 & Acceptable \\
\hline
\end{tabular}




\section{RESEARCH FINDINGS AND DISCUSSION}

\subsection{Response Rate}

Questionnaires were administered to 312 respondents who made up of both registered voters in Nairobi County and IEBC officials in Nairobi County. Out of 312 questionnaires distributed, 271 questionnaires were duly filled and returned. However, some of the respondents returned the questionnaires half-filled, while the others did not return them completely despite an intensive follow up. The response rate result is shown in Table 4.1. The study, therefore, yielded an $86.86 \%$ response rate, which, according to Bailey (2000), was very good for this study. Bailey (2000) believes that a response rate of $50 \%$ is adequate, while a response rate higher than $70 \%$ is outstanding.

Table 4.1: Response Rate

\begin{tabular}{lll}
\hline Response & Frequency & Percentage \\
\hline Returned & 271 & 86.86 \\
Unreturned & 41 & 13.14 \\
\hline Total & $\mathbf{3 1 2}$ & $\mathbf{1 0 0}$ \\
\hline
\end{tabular}

\subsection{Distribution of Respondents by Demographic Characteristics}

\subsubsection{Gender of the Respondents}

The majority $(66 \%)$ of respondents who took part in this study were males, while $34 \%$ were females as shown in Figure 4.1.

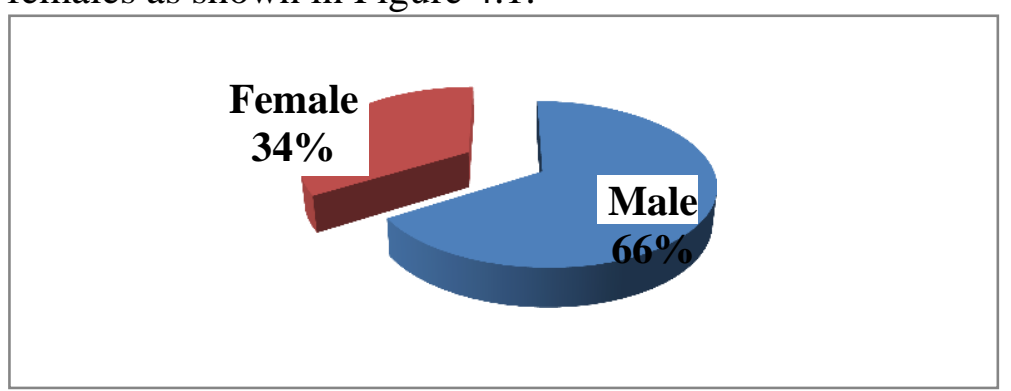

Figure 4.1 Gender of respondents

\subsubsection{Age of the Respondents}

Based on the results in Figure 4.2, most $(42.10 \%)$ of the respondents were between the age of 3140 years, $17.30 \%$ were between the ages of $26-30$ years, $14.40 \%$ were aged more than 50 years. Also, the results show that $13.70 \%$ of the respondents were aged between 18-25 years, and only $12.50 \%$ were aged between 41-50 years. The results imply that most of the registered voters in Nairobi County are between the ages of 31-40 years. This further implies that this age group is well informed about their rights to vote and elect the leaders they want, this age group is further the most affected by unemployment and therefore they exercise their right to vote to choose leaders who will create job opportunities for them. The results also imply that voters aged 41 years and above were not many since they have voted for a long time and perhaps they have not realized the change they have always wanted and so they no longer want to participate in the exercise, hence, voter apathy. Holland (2013) indicated that, in 2008 and 2012, younger people overwhelmingly voted for the Democratic candidate Barack Obama, while older people voted for the Republican candidate John McCain and Mitt Romney by wide margins; younger people are 
usually more liberal than older people, and younger people typically prefer insurgent candidates over mainstream candidates compared to older people.

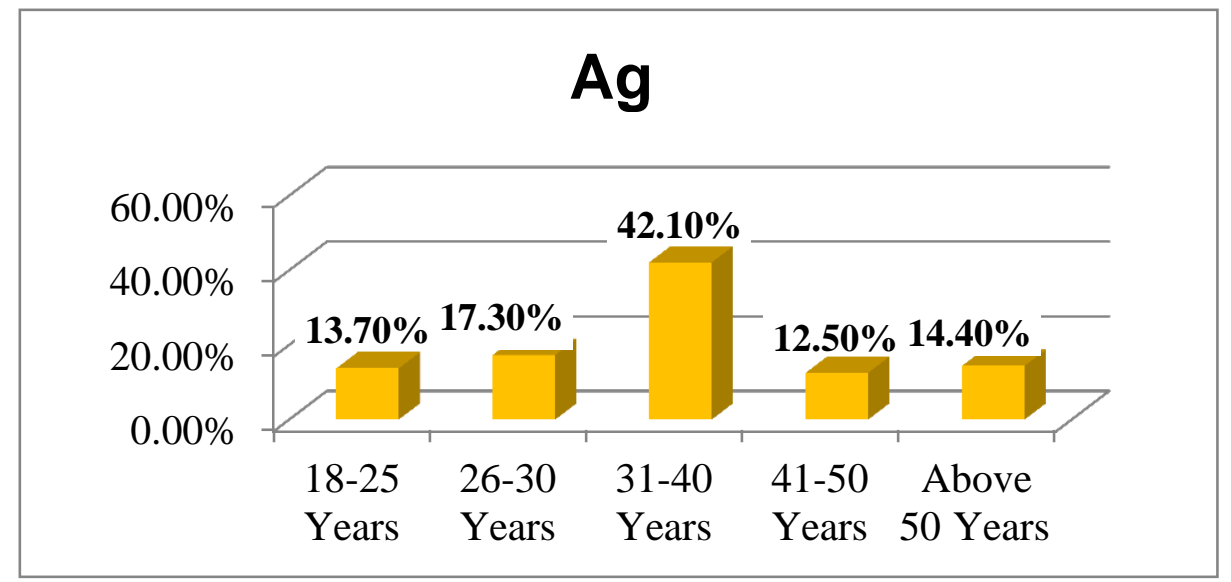

Figure 4.2: Age of Respondent

\subsubsection{Respondent's level of Education}

The results in Figure 4.3 show that slightly more than half of the respondents were secondary school graduates, $14 \%$ indicated that their highest level of education was college and another $14 \%$ indicated that their highest level of education was undergraduate. In addition, the results show that $11.40 \%$ of the respondents were postgraduates, while $10.30 \%$ indicated that the highest level of education they attained was the primary level. The results imply that most of the registered voters in Nairobi County are secondary school graduates.

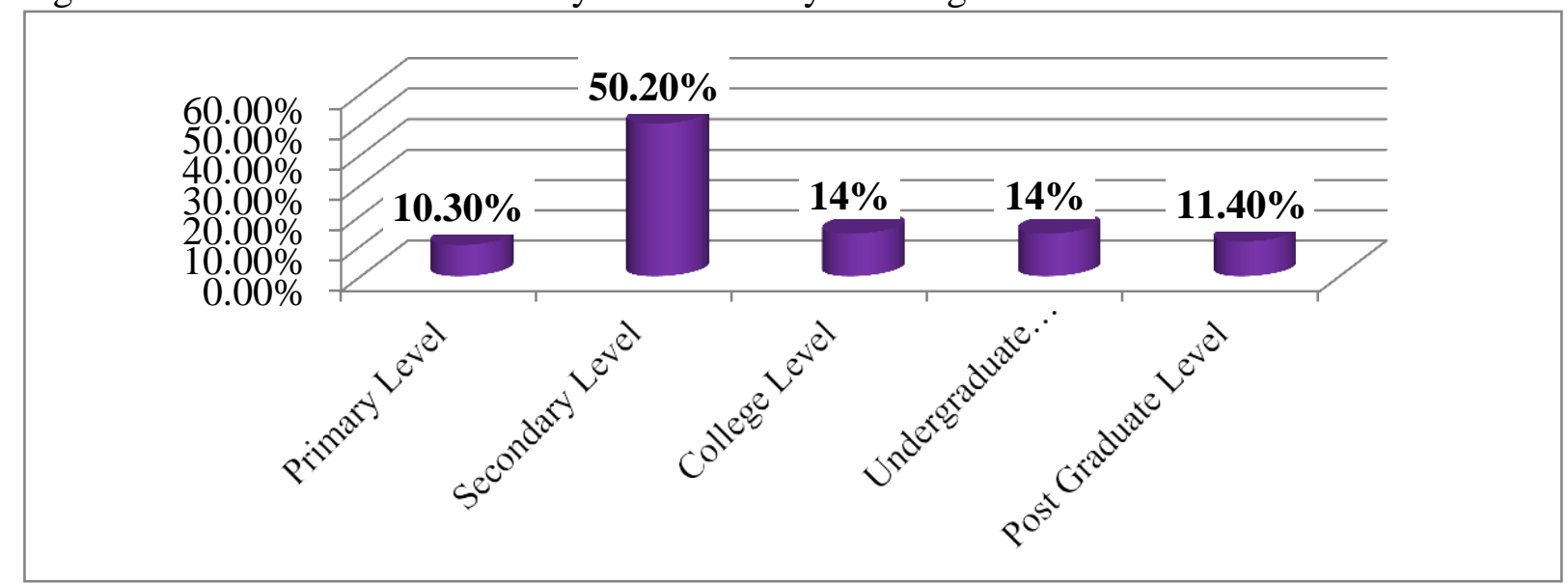

Figure 4.3: Highest Education Level

\subsubsection{Number of Times Voted in Nairobi County}

As indicated in Figure 4.4, slightly more than half of the respondents had voted in Nairobi County only once, $27 \%$ indicated that they had voted twice, and only $21 \%$ noted that they had never taken part in any voting process in a general election in Nairobi County. The results imply that most of the voters in Nairobi County have only participated in one general election in Nairobi County as voters. 


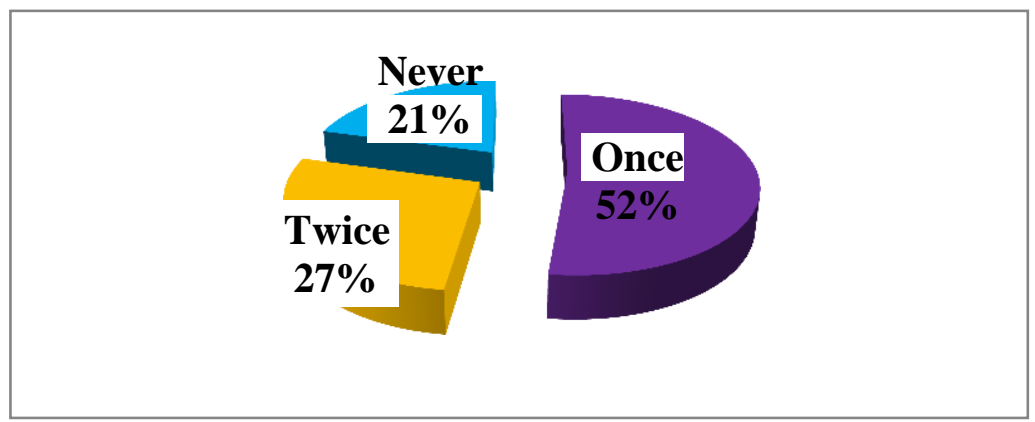

Figure 4.4: Number of Times Respondent had Voted in Nairobi county

\subsection{Descriptive Statistics}

\subsubsection{Descriptive Statistics on Candidates Registration System (CRS)}

The first objective of this study was to assess the importance of the candidate ${ }^{\text {ee }}$ registration system (CRS) on the credibility of the electoral system. The descriptive statistics for the candidate ${ }^{e s}$ registration system (CRS) are presented in Table 4.1

Table 4.1: Descriptive Statistics on Candidate's Registration System (CRS)

\begin{tabular}{|c|c|c|c|c|c|c|c|}
\hline Statement & $\begin{array}{l}\text { Strongly } \\
\text { Disagree }\end{array}$ & Disagree & Neutral & Agree & $\begin{array}{l}\text { Strongl } \\
\text { y Agree }\end{array}$ & Mean & $\begin{array}{l}\text { Std. } \\
\text { Dv }\end{array}$ \\
\hline $\begin{array}{l}\text { CRS ensures the candidates are } \\
\text { identified uniquely during elections }\end{array}$ & $0.70 \%$ & $0.70 \%$ & $2.60 \%$ & $38.40 \%$ & $57.60 \%$ & 4.513 & 0.660 \\
\hline $\begin{array}{l}\text { CRS ensures non registered persons } \\
\text { to vie for any political seat do not } \\
\text { find themselves in the ballot }\end{array}$ & $4.80 \%$ & $1.10 \%$ & $1.50 \%$ & $31.40 \%$ & $61.30 \%$ & 4.432 & 0.959 \\
\hline $\begin{array}{l}\text { Early registration of candidates } \\
\text { eliminates cases of imposters }\end{array}$ & $1.50 \%$ & $1.10 \%$ & $1.50 \%$ & $40.60 \%$ & $55.40 \%$ & 4.472 & 0.724 \\
\hline $\begin{array}{l}\text { CRS ensures the information about } \\
\text { the candidates are distributed to the } \\
\text { county level early enough and avoid } \\
\text { cases of double registration }\end{array}$ & $1.80 \%$ & $1.10 \%$ & $0.70 \%$ & $47.60 \%$ & $48.70 \%$ & 4.402 & 0.738 \\
\hline $\begin{array}{l}\text { CRS ensures no candidate is left out } \\
\text { of the ballot paper }\end{array}$ & $6.30 \%$ & $2.60 \%$ & $4.40 \%$ & $33.20 \%$ & $53.50 \%$ & 4.251 & 1.090 \\
\hline $\begin{array}{l}\text { CRS has helped reduce cases of } \\
\text { violence after elections since the } \\
\text { information about each and every } \\
\text { candidate is well captured for } \\
\text { reference. }\end{array}$ & $5.90 \%$ & $2.60 \%$ & $4.10 \%$ & $34.30 \%$ & $53.10 \%$ & 4.262 & 1.069 \\
\hline Average & & & & & & 4.389 & 0.873 \\
\hline
\end{tabular}

Results in Table 4.5 show that majority of the respondents $96.00 \%(38.40 \%+57.60 \%)$ were in agreement with the statement CRS ensures the candidates are identified uniquely during elections, and in so doing, the credibility of the election results is enhanced. The results also show that only $1.40 \%$ of the respondents had a different opinion on the statement. The result had a mean of 4.513 and a standard deviation of 0.660 , implying that most of the respondents were in agreement with the statement. The findings concur with assertion by LWV, Porte, and MAL 
(2019) that, CRS ensures that primary data on candidates nominated by political parties are entered in a format that makes it easy for IEBC to verify the accuracy of the candidate details, compliance and generate ballot paper proofs; this is achieved by cross-matching the voters register and political party register. Based on the results, $92.70 \%$ of the respondents believed that CRS ensures non registered persons to vie for any political seat do not find themselves in the ballot, while only $5.90 \%$ of the respondents had a contrary opinion on the same. The results had $(\mathrm{M}=4.432$, Std. $\mathrm{Dv}=0.959)$. This means that most of the respondents agreed with the statement however their responses were spread about the mean as indicated by the standard deviation.

The results further show that the majority $(96.00 \%)$ of the respondents were of the opinion that Early registration of candidates eliminates cases of imposters, and this, according to them helps in addressing the problem of credibility of the electoral body. However, $2.60 \%$ of the respondents held a different opinion; they believed early registration of candidates could not eliminate cases of imposters. The responses had $(M=4.472$, Std. Dv=0.724), showing that most of the respondents were in agreement with the statement. Besides, as shown, $96.30 \%$ of the respondents were holding the belief that CRS ensures the information about the candidates are distributed to the county level early enough and avoid cases of double registration, $2.90 \%$ of the respondents believed otherwise. The results had ( $M=4.402$, Std. Dv=0.738) showing that majority of the respondents agreed with the statement that CRS ensures the information about the candidates is distributed to the county level early enough and avoid cases of double registration. Similarly, the results show that majority $(86.70 \%)$ of the respondents agreed that with the statement that CRS ensures no candidate is left out of the ballot paper; however, $8.90 \%$ were holders of a contrary opinion regarding the same statement. The responses had (M=4.251, Std. Dev. $=1.090$ ) indicating that most of the respondents were in agreement with the statement even though the responses were varied. Finally, the results show that majority $(87.40 \%)$ of the respondents believed that CRS had helped reduce cases of violence after elections since the information about every candidate is well captured for reference, while $8.50 \%$ felt it had not. The response had $(M=4.303$, Std. Dev. =1.077). The results show that most of the respondents agreed with the statement, but the responses were varied. Overall, the results had an average mean and standard deviation of 4.389 and 0.873 respectively, showing that most of the respondents agreed with the statement, but the responses were varied. The results are consistent with the conclusion made by Jones, McAllister, and Gow (2018) that, it is good practice to ensure that the legal framework specifies when, how and where registration procedures must be undertaken, what the requirements for registration are and how the verification of registration will take place.

\subsubsection{Descriptive Statistics on Results Transmission System (RTS)}

The second objective of this study was to evaluate the consequence of results transmission system (RTS) on the credibility of the Electoral System. The descriptive statistics results on transmission system (RTS) are presented in Table 4.2. Results in Table 4.2 show that majority of the respondents $94.90 \%(39.10 \%+56.80 \%)$ were in agreement with the statement RTS had introduced transparency in the poll results and so the credibility of the election results had been enhanced by the electoral body IEBC. The results also show that $1.40 \%$ of the respondents did not agree with the statement. The result had a mean of 4.506 and a standard deviation of 0.660 , indicating that most of the respondents were in agreement with the statement. The result is consistent with what Thakur (2015) found that, with paper-based processes, collecting and 
calculating results from thousands of polling stations country-wide is a prolonged part process; but with digital technology, results can be transmitted electronically (for example, over the internet or by mobile phone) and aggregated by computer, allowing at least preliminary results to be announced quickly hence enhancing transparency in election. Also, based on the results, 93.00\% of the respondents believed that RTS ensures faster transmission of poll results reducing chances of manipulation, while only $5.50 \%$ of the respondents disagreed. The results had $(\mathrm{M}=4.376$, Std. $\mathrm{Dv}=0.930)$. This implies that most of the respondents agreed with the statement however their responses were spread about the mean as indicated by the standard deviation.

Table 4.2: Descriptive Statistics on Results Transmission System (RTS)

\begin{tabular}{|c|c|c|c|c|c|c|c|}
\hline Statement & $\begin{array}{l}\text { Strongly } \\
\text { Disagree }\end{array}$ & Disagree & Neutral & Agree & $\begin{array}{l}\text { Strongl } \\
\text { y Agree }\end{array}$ & Mean & $\begin{array}{l}\text { Std. } \\
\text { Dv }\end{array}$ \\
\hline $\begin{array}{l}\text { RTS has introduced transparency in } \\
\text { the poll results }\end{array}$ & $0.70 \%$ & $0.70 \%$ & $2.60 \%$ & $39.10 \%$ & $56.80 \%$ & 4.506 & 0.660 \\
\hline $\begin{array}{l}\text { RTS ensures faster transmission of } \\
\text { poll results reducing chances of } \\
\text { manipulation }\end{array}$ & $4.40 \%$ & $1.10 \%$ & $1.50 \%$ & $38.40 \%$ & $54.60 \%$ & 4.376 & 0.930 \\
\hline $\begin{array}{l}\text { With the adoption of RTS, there is } \\
\text { openness in the transmission of pole } \\
\text { results }\end{array}$ & $1.50 \%$ & $1.10 \%$ & $1.50 \%$ & $41.70 \%$ & $54.20 \%$ & 4.461 & 0.724 \\
\hline RTS reduces anxiety among voters & $1.80 \%$ & $1.10 \%$ & $0.70 \%$ & $46.90 \%$ & $49.40 \%$ & 4.410 & 0.739 \\
\hline $\begin{array}{l}\text { RTS has reduced rigging in elections } \\
\text { in Kenya }\end{array}$ & $5.90 \%$ & $2.20 \%$ & $4.40 \%$ & $37.60 \%$ & $49.80 \%$ & 4.232 & 1.055 \\
\hline RTS guarantees integrity of the results & $5.50 \%$ & $2.20 \%$ & $4.10 \%$ & $34.30 \%$ & $53.90 \%$ & 4.288 & 1.043 \\
\hline Average & & & & & & 4.379 & 0.858 \\
\hline
\end{tabular}

The results further show that majority $(95.90 \%)$ of the respondents was of the opinion that with the adoption of RTS, there is openness in the transmission of pole results. However, $2.60 \%$ of the respondents held a contrary opinion; they believed with the adoption of RTS, there is still no openness in the transmission of pole results. The responses had $(\mathrm{M}=4.461$, Std. $\mathrm{Dv}=0.724)$ showing that most of the respondents were in agreement with the statement. In addition, as shown, $96.30 \%$ of the respondents were holding the belief that RTS reduces anxiety among voters, while $2.90 \%$ of them felt otherwise. The results had $(M=4.410$, Std. $D v=0.739)$ showing that majority of the respondents agreed with the statement that RTS reduces anxiety among voters. Similarly, the results show that majority $(87.40 \%)$ of the respondents agreed that with the statement that RTS has reduced rigging in elections in Kenya; however, $8.10 \%$ felt it had not. The responses had $(\mathrm{M}=4.232$, Std. Dev. $=1.055)$ indicating that most of the respondents were in agreement with the statement even though the responses were varied. Finally, the results show that majority $(88.20 \%)$ of the respondents were of the opinion that RTS guarantees integrity of the results, while $7.70 \%$ held a contrary opinion. The response had $(\mathrm{M}=4.288$, Std. Dev. =1.043). The results show that most of the respondents agreed with the statement but the responses were varied. Overall, the results had an average mean and standard deviation of 4.379 and 0.858 respectively showing that most of the respondents agreed with the statement but the responses were varied. The results are consistent with the findings of Loeber (2017) which indicated that, the applications used to ensure the security of data include electoral registers, software for registration of parties and candidates and software for tallying, direct data capture machines and 
calculating results. However, nowadays, voters are also confronted with ICT solutions in voting in some countries where forms of e-voting are introduced.

\subsubsection{Credibility of the Electoral System}

The dependent variable of this study was the credibility of the Electoral System. Based on the results presented in Table 4.4, majority $95.20 \%(41.00 \%+54.20 \%)$ had the feeling that over the previous two general elections, IEBC had ensured inclusivity in the electoral process. However, $1.80 \%$ of them believed otherwise. The result had a mean of 4.458 and a standard deviation of 0.728 , indicating that most of the respondents were in agreement with the statement.

Table 4.4: Descriptive Statistics on the Credibility of the Electoral System

\begin{tabular}{|c|c|c|c|c|c|c|c|}
\hline Statement & $\begin{array}{l}\text { Strongly } \\
\text { Disagree }\end{array}$ & Disagree & Neutral & Agree & $\begin{array}{l}\text { Strongly } \\
\text { Agree }\end{array}$ & Mean & $\begin{array}{l}\text { Std. } \\
\text { Dev }\end{array}$ \\
\hline \multicolumn{8}{|l|}{ Over the past two general elections } \\
\hline $\begin{array}{l}\text { IEBC has ensured inclusivity in the } \\
\text { electoral process }\end{array}$ & $1.80 \%$ & $0.00 \%$ & $3.00 \%$ & $41.00 \%$ & $54.20 \%$ & 4.458 & 0.728 \\
\hline \multicolumn{8}{|l|}{$\begin{array}{l}\text { There has been an increase in openness } \\
\text { in the manner in which elections are }\end{array}$} \\
\hline being held in Kenya & $4.40 \%$ & $0.70 \%$ & $2.60 \%$ & $38.40 \%$ & $53.90 \%$ & 4.365 & 0.929 \\
\hline $\begin{array}{l}\text { IEBC has been delivering free fair and } \\
\text { credible elections since promulgation } \\
\text { of } 2010 \text { constitution. }\end{array}$ & $1.50 \%$ & $0.40 \%$ & $1.50 \%$ & $43.90 \%$ & $52.80 \%$ & 4.461 & 0.692 \\
\hline \multicolumn{7}{|l|}{$\begin{array}{l}\text { IEBC has gained public trust in the } \\
\text { manner in which they conduct }\end{array}$} & 0.707 \\
\hline $\begin{array}{l}\text { Because of the integrity of the results } \\
\text { delivered by IEBC, there has been a } \\
\text { reduction in tension after pols }\end{array}$ & $7.00 \%$ & $1.80 \%$ & $4.40 \%$ & $32.10 \%$ & $54.60 \%$ & 4.255 & 1.111 \\
\hline $\begin{array}{l}\text { Election petitions have reduced } \\
\text { drastically since the introduction of } \\
\text { biometric voting. }\end{array}$ & $5.90 \%$ & $0.80 \%$ & $4.10 \%$ & $33.90 \%$ & $54.20 \%$ & 4.288 & 1.053 \\
\hline Average & & & & & & 4.371 & 0.870 \\
\hline
\end{tabular}

The result conforms with the findings of Ibrahim (2019) which revealed that, in 2013, Kenyan election was a classic case where the Independent Electoral and Boundaries Commission (IEBC) in partnership with the media made efforts to educate voters weeks before the general elections as a way of increasing the credibility of the election results by reducing the number of spoilt votes. Also based on the results, $92.30 \%$ of the respondents believed that there had been an increase in openness in the manner in which elections were being held in Kenya. Conversely, $5.10 \%$ believed that there had never been any change in the openness in the manner in which elections were being held in Kenya. The results had $(M=4.365$, Std. Dev=0.929). This implies that most of the respondents had the feeling that there had been an increase in openness in the manner in which elections were being held in Kenya; however, their responses were spread about the mean as indicated by the standard deviation. The results further show that majority (96.70\%) of the respondents thought that IEBC had been delivering free, fair and credible elections since the promulgation of 2010 constitution. However, $1.90 \%$ of the respondents held a contrary opinion; they believed IEBC had not delivered free, fair and credible elections since promulgation of 2010 constitution. The responses had $(M=4.461$, Std. $\mathrm{Dv}=0.692)$, showing that 
most of the respondents were in agreement with the statement. In addition, as shown, $97.10 \%$ of the respondents were holding the belief that IEBC had gained the public trust in the manner in which they conduct elections, while $2.90 \%$ of the them felt otherwise. The results had $(\mathrm{M}=4.410$, Std. Dv=0.739) showing that majority of the respondents agreed with the statement.

Similarly, the results show that majority $(86.70 \%)$ of the respondents agreed that because of the integrity of the results delivered by IEBC, there had been reduction in tension after pols; however, $8.80 \%$ did not agree. The responses had $(M=4.255$, Std. $D v=1.111)$ indicating that most of the respondents were in agreement with the statement even though the responses were varied. Finally, the results show that majority $(88.10 \%)$ of the respondents were of the opinion that election petitions had reduced drastically since the introduction of biometric voting system by IEBC, while $6.70 \%$ believed nothing had changed. The response had $(\mathrm{M}=4.288$, Std. $\mathrm{Dv}=1.053)$. The results show that most of the respondents agreed with the statement but the responses were varied. Overall, the results had an average mean and standard deviation of 4.371 and 0.870 respectively showing that most of the respondents agreed with the statement, but the responses were varied.

\subsection{Inferential Analysis \\ 4.4.1 Correlation Analysis}

In this study, correlation analysis was conducted to establish the relationship of candidate registration systems (CRS) on the credibility of the Electoral System and to determine the relationship of Results Transmission System (RTS) on the credibility of the Electoral System. The correlation results are presented in Table 4.5

Table 4.5: Multiple Correlation Matrix

\begin{tabular}{lllll}
\hline & & Credibility & CRS & RTS \\
\hline Credibility & Pearson Correlation & 1.000 & & \\
& Sig. (2-tailed) & & & \\
CRS & Pearson Correlation & $.554^{* *}$ & 1.000 & \\
& Sig. (2-tailed) & 0.000 & & \\
RTS & Pearson Correlation & $.648^{* *}$ & $.433^{* *}$ & 1.000 \\
& Sig. (2-tailed) & 0.000 & 0.000 & \\
\hline
\end{tabular}

** Correlation is significant at the 0.01 level (2-tailed).

The results in Table 4.5 revealed that that candidate registration systems and the credibility of electoral systems are positively and significantly associated as indicated by $(\mathrm{r}=0.554, \mathrm{p}=0.000)$. Finally, the correlation results indicated that there was a positive and significant association between results transmission and presentation system and credibility of electoral systems as shown by $(\mathrm{r}=0.648, \mathrm{p}=0.000)$. The correlation results affirm the assertion by Jacobsen (2019) that increased internet penetration even in developing countries with poor communications infrastructure is enabling EMBs to be more effective at communicating internally and with all the stakeholders involved in the process. Technology is also playing an increased role in enhancing the integrity and credibility of electoral processes and strengthening trust between stakeholders. 


\subsubsection{Regression Analysis}

The regression analysis was conducted to establish the combined effect of candidate registration systems (CRS) and Results Transmission System (RTS) on the credibility of the electoral system. The results presented in Table 4.6 indicate the fitness of the model which was interpreted using the R squared value. The model fitness results in Table 4.6 show that CRS, and RTS are satisfactory variables in explaining the credibility of electoral system. This is supported by a coefficient of determination also known as the R square of 0.783 . This means that CRS, and RTS explain $78.3 \%$ of the variations in the dependent variable, which in this case is the credibility of the electoral system.

Table 4.6: Model Fitness

\begin{tabular}{|c|c|c|c|c|}
\hline Model & $\mathbf{R}$ & R Square & Adjusted R Square & $\begin{array}{l}\text { Std. Error of the } \\
\text { Estimate }\end{array}$ \\
\hline 1 & $.885^{\mathrm{a}}$ & .783 & .780 & .30706 \\
\hline
\end{tabular}

The results are consistent with the findings of Ayeni and Esan (2018) which indicated that, the incorporation of Technology in Nigeria electoral process had reduced excessive electoral fraud to the barest minimum and foster credible election. The study further noted that the introduction of technology in the Nigerian electoral system had modernized the system and improved election management in the country and enhanced the credibility of the election results. Table 4.7 shows the results of the Analysis of Variance (ANOVA).

Table 4.7: Analysis of Variance

\begin{tabular}{lllllll}
\hline Model & & Sum of Squares & Df & Mean Square & F & Sig. \\
\hline \multirow{4}{*}{1} & Regression & 90.677 & 4 & 22.669 & 240.425 & $.000^{\mathrm{b}}$ \\
& Residual & 25.081 & 266 & .094 & & \\
& Total & 115.757 & 270 & & & \\
\hline
\end{tabular}

a. Dependent Variable: Credibility

b. Predictors: (Constant), BVR, EVID

The ANOVA results in Table 4.7 show that the general model was statistically significant. Further, the outcomes suggest that the independent variables (CRS, and RTS) were good indicators of the credibility of the electoral system. This was supported by an F statistic of 240.425 and the reported p-value (0.000) which was less than the conventional probability of 0.05 significance level. The regression of the coefficient table is presented in Table 4.8.

\begin{tabular}{cllllll}
\hline \multirow{2}{*}{ Model } & & \multicolumn{2}{l}{ Unstandardized Coefficients } & $\begin{array}{l}\text { Standardized } \\
\text { Coefficients }\end{array}$ & \\
\cline { 2 - 5 } & & B & Std. Error & Beta & & S \\
\hline & (Constant) & -.119 & .148 & & -.806 & .421 \\
& CRS & .152 & .030 & .170 & 5.151 & .000 \\
& RTS & .155 & .033 & .173 & 4.733 & .000 \\
\hline
\end{tabular}

a. Dependent Variable: Credibility 
The optimal model was therefore;

$\mathrm{Y}=-.119+0.152 \mathrm{X}_{1}+0.155 \mathrm{X}_{2}$

Where:- $\mathrm{Y}=$ Credibility of Electoral System; $\mathrm{X}_{1}=\mathrm{CRS} ; \mathrm{X}_{2}=\mathrm{RTS}$

Regression of coefficients results in Table 4.8 shows that candidate registration systems and the credibility of electoral systems were positively and significantly related $(\beta=.152, p=0.000)$. Similarly, the results show that there was a positive and significant relationship between result transmission system and the credibility of electoral systems $(\beta=.155, \mathrm{p}=0.000)$. This implies that an improvement in CRS and RTS leads to an improvement in the credibility of electoral systems. The regression results are consistent with the findings of Loeber (2017), which indicated that, the applications used for ensuring the security of data include; electoral registers, software for registration of parties and candidates and software for tallying, direct data capture machine and calculating results. However, nowadays, voters are also confronted with ICT solutions in voting in some countries where forms of e-voting are introduced. This can range from fairly simple forms such as a scanner that counts the ballot as the voter puts it in the ballot box, to the use of voting computers in the polling station, but also remote voting through the internet. The use of these new technologies raises new challenges for election management bodies (EMB).

\section{SUMMARY, CONCLUSIONS, AND RECOMMENDATIONS}

\subsection{Summary of findings}

\subsubsection{Candidate's Registration System (CRS) and Credibility of Electoral System}

The first objective of this study was to assess the importance of the candidate ${ }^{\text {ee }}$ registration system (CRS) on the credibility of the electoral system. Descriptive statistics were conducted on the sub-variables of the candidate $\mathrm{s}$ registration system, and the findings revealed that the majority of the respondents were in agreement with the statements $(M=4.389$; Std. Dv=0.873). Correlation analysis results revealed that candidate registration systems and credibility of electoral systems were positively and significantly associated ( $\mathrm{r}=0.554, \mathrm{p}=0.000)$. The correlation result indicated that there was a strong positive association between CRS and the credibility of the electoral system. Also, a regression analysis was conducted, and the findings were that there was a positive and significant relationship between CRS and the credibility of IEBC $(\beta=.152, p=0.000)$. This means that a unit improvement in CRS in the election process leads to an improvement in the credibility of the electoral system by 0.152 units.

\subsubsection{Results Transmission System (RTS) on Credibility of Electoral System}

The second objective of this study was to evaluate the consequence of results transmission system (RTS) on the credibility of the Electoral System. This was done by conducting descriptive statistics on the statements of the variables. Furthermore, a correlation analysis was done to establish the association between the variable and the dependent variable. Finally, a regression analysis was conducted to establish the relationship between the variables. The descriptive statistics results indicated that most of the respondents were in agreement with the statements of RTS $(\mathrm{M}=4.379 ; \mathrm{Std}$. $\mathrm{Dv}=0.858)$. The correlation analysis results revealed a positive and significant association between RTS and the credibility of the electoral system $(\mathrm{r}=0.648, \mathrm{p}=0.000)$. The regression analysis results indicated that RTS and credibility of results were positively and significantly related $(\beta=.155, \mathrm{p}=0.000)$, which meant that, a unit improvement in RTS would result in an improvement in credibility by 0.155 units. 


\subsection{Conclusions}

The study concludes that CRS positively and significantly affects the credibility of the electoral system; the CRS ensures that primary data on candidates nominated by political parties are entered in a format that makes it easy for IEBC to verify the accuracy of the candidate details, compliance and generate ballot paper proofs. The study concludes that it is necessary to register candidates who wish to take part in an election process because the nomination of candidates is the formal procedure by which political parties and individuals put candidates forward for election and the acceptance of the EMB of that nomination. In list systems, parties put forward a list of candidates selected within the political party. In constituency systems, candidates are nominated individually; they can be nominated either by a political party or by an individual. It is, therefore, important that the electoral body registers them to keep away imposters.

Finally, the study concludes that results transmission system (RTS) is vital in enhancing the credibility of IEBC. It is because when results are transmitted electronically, there is enhanced transparency through electronic transmission of provisional results from the polling stations. There is a display and visualized provisional results at the tally centers, which also provides access to provisional elections data to media and other stakeholders in real-time. Also, in the long term, expenses are expected to decrease. Results can be reported and published faster. Although transparency is always fundamental, it holds particular importance during the stage in which preliminary results are transmitted and made public. It is essential that candidates and political party representatives sign and obtain a copy of the voting account and that they have the opportunity to witness the transmission of results to electoral organisms.

\subsection{Recommendations}

The study recommends to IEBC that they should strive to plan early enough so that by the time the elections begin they will have tested all their equipment and confirm that they are fit to be used in the process and ensure proper training of their personnel on the election technologies and processes. This will increase the credibility of the electoral system. The government and the legislature on their part should strive to provide the necessary support to the EMB in terms of a timely legal framework, adequate finances, and appropriate security to ensure timely procurement of required election material.

\section{References}

Abodunrin, O., Oloye, G., \& Alaba, A. (2018). Technology-Based Device And Electoral Process In Nigeria. Global Journal of Applied, Management, and Social Sciences, 15.

Achieng, M., \& Ruhode, E. (2013). The adoption and challenges of electronic voting technologies within the South African context. arXiv preprint arXiv:1312.2406.

Agbu, O. (2016). Election rigging and the use of technology: the Smart Card Reader as the Joker in Nigeria"s 2015 Presidential Election. Journal of African Elections, 15(2), 90-111.

Alhassan, A. A. (2018). The Role and Use of Social Media in Elections Campaigns and Voting Behavior in Nigeria: An Analysis of the 2015 Presidential Election. International Journal of Recent Innovations in Academic Research, 2(6), 117-129.

Ashwini, S. N., Ashwini, K. C., Belavatagi, B. I., Kumuda, B., \& Bhaskar, S. V. (2017). Aadhar and Biometric Based Electronic Voting Machine. Perspectives in Communication, Embedded-systems, and Signal-processing-PiCES, 1(8), 145-148. 
Birch, S., \& Muchlinski, D. (2018). Electoral violence prevention: what works?. Democratization, 25(3), 385-403.

Borner, S., Brunetti, A., \& Weder, B. (2016). Political credibility and economic development. Springer.

Cheeseman, N., Kanyinga, K., Lynch, G., Ruteere, M., \& Willis, J. (2019). Kenya ${ }^{\text {ee }} 2017$ elections: winner-takes-all politics as usual?. Journal of Eastern African Studies, 13(2), 215-234.

Cheeseman, N., Lynch, G., \& Willis, J. (2018). Digital dilemmas: The unintended consequences of election technology. Democratization, 25(8), 1397-1418.

Cooper, D. R., \& Schindler, P. S, 2001, Business Research Methods.

Cooper, D. R., \& Schindler, P. S. (2008). Business research methods (Vol. 2). London: McGrawHill Higher Education.

Dorpenyo, I. K. (2019). Risky Election, Vulnerable Technology: Localizing Biometric Use in Elections for the Sake of Justice. Technical Communication Quarterly, 1-15.

Fisher L. B., Isa W., Bryn A., Carlos A. C., Graham A. C.(2007). Predictors of Initiation of Alcohol Use Among US Adolescents. Findings From a Prospective Cohort Study.Arch Pedriatr Adolesc Med,161, 959-966.

Gates, B. (2018). Chapter Twelve Technology And Mediated Social Presence. Musings on the Teacher's Art, 131.

Heale, R., \& Twycross, A. (2015). Validity and reliability in quantitative studies. Evidencebased nursing, 18(3), 66-67.

Holland, J. L. (2013). Age Gap? The Influence of Age on Voting Behavior and Political Preferences in the American Electorate.

Iwuoha, V. C. (2018). ICT and elections in Nigeria: rural dynamics of biometric voting technology adoption. Africa Spectrum, 53(3), 89-113.

Jacobsen, K. L. (2019). Biometric voter registration: A new modality of democracy assistance?. Cooperation and Conflict, 0010836719850219.

Jones, R., McAllister, I., \& Gow, D. (2018). Australian election study, 1996.

Kanyinga, K., \& Odote, C. (2019). Judicialisation of politics and Kenyae 2017 elections. Journal of Eastern African Studies, 13(2), 235-252.

Kenny, C. (2019). „Women Are Not Ready to [Vote for] Their Own "e: Remaking Democracy, Making Citizens After the 2007 Post-Election Violence in Kenya. In Rethinking Transitional Gender Justice (pp. 273-294). Palgrave Macmillan, Cham.

Laakso, L. (2019). Electoral Violence and Political Competition in Africa. In Oxford Research Encyclopedia of Politics.

Lindner, J. R. (2018). The Importance of Understanding the Technology that Serves Us. Journal of the American Society of Echocardiography, 31(7), A27-A28.

Loeber, L. (2017). The use of technology in the election process: Who governs?. Second In, 187.

LWV, V., Porte, J., \& MAL, L. A. A. (2019). Early Voting.

Momani, A., \& Jamous, M.(2017). The Evolution of Technology Acceptance Theories, International Journal of Contemporary Computer Research (IJCCR), Vol 1, 50-58.

Micheni, E., \& Murumba, J. (2018, May). The Role of ICT in Electoral Processes: Case of Kenya. In 2018 IST-Africa Week Conference (IST-Africa) (pp. Page-1). IEEE.

Nespeca, V., Meesters, K., Comes, T., Boersma, K., \& Tomaszewski, B. (2018). Evaluating Platforms for Community Sense-making: Using the Case of the Kenyan Elections. In ISCRAM. 
Norris, P., Cameron, S., \& Wynter, T. (Eds.). (2018). Electoral Integrity in America: Securing Democracy. Oxford University Press, USA.

Okokpujie, K. O., John, S. N., Noma-Osaghae, E., Ndujiuba, C., \& Okokpujie, I. P. (2019). An Enhanced Voters Registration And Authentication Application Using Iris Recognition Technology. International Journal of Civil Engineering and Technology (IJCIET), 10(2), 57-68.

Orodho, A. J., \& Kombo, D. K. (2002). Research methods. Nairobi: Kenyatta University, Institute of Open Learning.

Rothenberg, D. (2018). STS 308-001: Technology and Global Development.

Saunders, M., Lewis, P., \& Thornhill, A. (2012). Research methods for business students (6. utg.). Harlow: Pearson.

Thakur, S. (2015). E-voting: India and the Philippines-a comparative analysis for possible adaptation in Africa. In Emerging Issues and Prospects in African E-Government (pp. 2855). IGI Global.

Van Holsteyn, J. J. (2018). The Dutch parliamentary elections of March 2017. West European Politics, 41(6), 1364-1377.

Venkatesh, V., Morris, M., Davis, G., \& Davis, F. (2003). User Acceptance of Information Technology: Toward a Unified View. MIS Quarterly, 27(3), 425-478.

von Borzyskowski, I. (2019). The credibility challenge: How democracy aid influences election violence. Cornell University Press.

Wolf, P., Alim, A., Kasaro, B., Namugera, P., \& Saneem, M. (2017). Introducing Biometric Technology in Elections. Stockholm: International Institute for Democracy and Electoral Assistance. 